\title{
The Challenge of Marking Relative Clauses in Turkish Sign Language ${ }^{*}$
}

\author{
Okan Kubus ${ }^{1}$, Derya Nuhbalaoğlu ${ }^{2}$ \\ ${ }^{1}$ Universität Hamburg, Fachbereich Sprache, Literatur, Medien I Institut für Deutsche \\ Gebärdensprache Gorch-Fock-Wall 720354 Hamburg \\ ${ }^{2}$ Georg-August-Universität Göttingen, Seminar für Deutsche Philologie Courant \\ Forschungszentrum "Textstrukturen "Nikolausberger Weg 23, 37073 Göttingen, Germany \\ ${ }^{1}$ okan.kubus@uni-hamburg.de, ${ }^{2}$ derya.nuhbalaoglu@uni-goettingen.de
}

(Rceived 11 November 2017; accepted 8 June 2018)

\begin{abstract}
This paper aims to show to what degree relativization strategies in Turkish Sign Language (TID) are influenced by discourse functions of relative clauses, extending Kubus' study (Kubus, 2016). In his study, Kubus describes various relativization strategies (i.e. internally headed, externally headed and free relatives) and identifies non-manual (i.e. squint, brow raise or slight-headshake) and occasionally additional manual relativizers (i.e. clause initial/final index (IX), AYNI 'same' or different combinations of them). We outline possible reasons for the presence of these competing relative markers and discuss whether the above-mentioned non-manuals should be analyzed as prosodic/pragmatic or syntactic markers. We suggest that the nature of relative clauses in TID can best be understood at the level of discourse.
\end{abstract}

Key words: relativization strategies, Turkish Sign Language, (non)-manual markers, optionality, discourse functions

\section{Türk İșaret Dili’nde İlgi Tümceciklerini Belirleme Sorunsalı}

ÖZ: Bu çalışma Türk İşaret Dili’nde (TiD) ilgi tümceciklerinin söylem işlevlerinden ne derecede etkilendiklerini, Kubus'un araştırmasını (Kubus, 2016) genişleterek göstermeyi amaçlamaktadır. Kubus, analizinde TiD'de farklı ilgi tümcecikleri (içten başlı, dıştan başlı ve özgür ilgi tümceciği) ve farklı el-dışı hareketleri (gözleri kısarak bakmak, kaş kaldırma ve başın hafifçe sallanması) ile ayrıca, sık görülmese de, ele ait ilgi tümceciği belirticileri (tümcecik başı/sonu INDEX (IX), AYNI ve bunların farklı şekillerde birleşimleri) olduğunu tespit etmektedir. Çalışmamızda bu belirticilerin

* Portions of this study were derived from the data analyzed in Kubus' dissertation and presented at the Workshop: Nonmanuals at the Gesture Sign Interface (NaGSI), Georg-August-Universität Göttingen, Göttingen, 9 - 10. Oktober 2015 and at an invited talk at Institut National des Langues et Civilisations Orientales - Inalco Paris, 15. December, 2017. We are grateful to two anonymous reviewers for their suggestions and feedback.

http://dx.doi.org/10.18492/dad.373454

Dilbilim Araştırmaları Dergisi, 2018/1, 139-160.

(C) 2017 Boğaziçi Üniversitesi Yayınevi, İstanbul. 
rekabet halinde olmalarının muhtemel sebepleri sıralanıp yukarıda bahsi geçen el-dışı hareketlerinin bürünsel/edimbilimsel mi yoksa sözdizimsel mi olduğu tartışılmakta ve TİD'deki ilgi tümceciklerinin doğasının en iyi söylem düzeyinde anlaşılabileceği önerilmektedir.

Anahtar sözcükler: ilgi tümcecikleri, Türk İşaret Dili, el-(dışı) belirticileri, seçimlilik, söylem işlevi

\section{Introduction}

This paper aims to extend the analysis of relativization strategies in Turkish Sign Language (Türk İşaret Dili, henceforth TID) by Kubus (2016). Kubus has shown that TiD exhibits various relativization strategies, i.e. internally headed, externally headed and free relatives. Among these, internally headed relativization strategy is the most frequent one and is usually accompanied by a squint. However, there are other non-manuals like brow raise and headshake as well. The biggest challenge regarding all types of relative clauses (RCs) is that some, but not all of them occur with relative clause markers with varying amount. We aim to understand the tendencies of the competing (non)-manual markers in different relativization strategies reanalyzing the data compiled by Kubus (2016). We present a descriptive and extended analysis of discourse functions of the head nouns (HNs) and modifying clauses (MCs), taking these competing strategies into consideration.

In the following, first we provide a background on RCs, outlining the the categorization, which will be referred to throughout the paper, and we give a short overview of the relativization strategies in sign languages (Section 2). Second, we present different relativization strategies in TiD based on the study by Kubus (2016) (Section 3). Third, we analyze the relationship between discourse functions and the competing strategies in relativization in TID (Section 4). Then we summarize the findings, discuss their implications as well as future prospects (Section 5) and finally conclude the paper (Section 6).

The goal of this paper is twofold: (i) to provide an overview of the interaction of relativization strategies with non-manual markers and manual markers and (ii) to determine to what degree relativization strategies can be influenced by the discourse functions of RCs, using statistical data from Kubus (2016).

\section{Background}

\subsection{Relative Clauses and Their Categorization}

There are various ways to define relativization strategies in spoken languages, for example, according to syntactic, functional or semantic criteria (Andrews, 
2007; M. De Vries, 2002; among others). Here we will focus specifically on the categorization done according to the presence/absence of the head and the (structural/hierarchical) position of the head with respect to RCs (M. De Vries, 2002: 18-19). In particular, RCs can have an overt head (headed relatives) or they can lack an overt head (free relatives), as exemplified in (1a-b) for English ${ }^{1}$.

(1) a. Jill ignored the advice which I gave to her.

b. Jill ignored what I told her.

In addition, (overt) relative heads can stay in different hierarchical relation to their dependent clauses that is, internally or externally, as in (2a) and (2b) respectively ${ }^{2}$.

(2) a. [Nuna bestya-ta ranti-shqa-n] alli bestya-m ka-rqo-n ${ }^{3}$. man horse-ACC buy-PERF-3 good horse-EVID be-PAST-3

'The horse that the man bought was a good horse.'

b. The horse that the man bought was a good horse.

Relative clauses with overt heads can further be realized as single headed, see (1a) and (2b) in English, or double headed. (3) is an example of a double headed relative from Kombai ((L. De Vries, 1993: 78) as cited in (Cinque, 2013: 224)). While the first $\mathrm{HN}$ is internal to the relative clause, the second one is interpreted as external to the relative clause (for the discussion, see also Cinque (2013: 224).

(3) [[doü adiyano-no] doü] deyalukhe

[[sago give.3PL.NONFUT-CONN] sago] finished.ADJ

'The sago that they gave is finished.'

\subsection{An Overview of RCs in Sign Languages}

What about relativization strategies within visual-gestural modality? Before discussing relativization strategies in sign languages, it is important to point out the discussion on the existence of complex sentences in these languages. Here we refer to the general overviews of complex sentences: Tang \& Lau

1 Note that the relative heads are italicized in the examples presented in this paper.

2 The details of categorization based on hierarchical position of the head will not be outlined here but the reader is referred to de Vries (2002) for the details.

3 Ancash Quechua (Cole, 1987: 277) 
(2012), Pfau \& Steinbach (2016) and the works therein, as well as Branchini $\&$ Kelepir (2017). These authors strongly indicate the significance of nonmanual behavior in the analysis of subordination, especially RCs.

Even though the interest in RCs in sign languages has increased over the last decades, this topic has not been investigated in detail yet. One of the sign languages intensively investigated for RCs is Italian Sign Language (LIS), for which there are competing analyses. In particular, RCs in LIS have been proposed to be correlatives (Cecchetto, Geraci, \& Zucchi, 2006), nominalized clauses (Branchini, 2015; Branchini \& Donati, 2007), relabeling structures (Cecchetto \& Donati, 2016), and internally headed and externally headed RCs (Brunelli, 2011). German Sign Language (DGS) has been proposed to exhibit externally headed relative clauses (EHRC) with relative pronoun, which have different variants for human and nonhuman referents (Pfau \& Steinbach, 2005). Likewise, Brazilian Sign Language has been shown to have EHRC constructions (Nunes \& de Quadros, 2008). On the other hand, in Hong Kong Sign Language (HKSL) (Tang, Lau, \& Lee, 2010) and Catalan Sign Language (LSC) (Mosella, 2011) internally headed relative clauses (IHRC) are more common. It has additionally been shown for LSC that IHRCs have a special manual relativizer MATEX $^{4}$ 'the same' (Mosella, 2011). Japanese Sign Language exhibits EHRC constructions, as well (Ichida (2010) as cited in Wilbur (2017: 3)). Israeli Sign Language (ISL) has been identified to have a special non-manual marker of relativization, squint (Dachkovsky \& Sandler, 2009). As an example of extreme case, Sign Language of the Netherlands does not have RCs (Brunelli, 2011). Wilbur (2017) has done a comparative study, which includes recent typological comparison of American Sign Language (ASL) (see also the seminal work of Liddell (1978, 1980)), LIS, and DGS RCs in terms of the correlation between the basic word order of these languages and the relative clause strategies they employ.

\section{Relativization Strategies in TiD}

Kubus (2016) investigated the RC constructions ${ }^{5}$ in TID, based on a smallscale corpus analysis. Kubus' corpus covers free storytelling collected throughout face-to-face situation (3 TID signers: one native, two near-native signers) and videos shared publicly (11 TID signers: four native, five nearnative signers and two nonnative-fluent signers) which are checked with these aforementioned signers. In sum, the duration of the video clips is

4 The gloss-signs are shown as small-capitalized text in this paper.

5 We would like to emphasize that the analysis of RCs in TíD is also based on the non-manuals, for example, the scope of squint and the break between the HNs and MCs are the criteria we use to identify RCs in this paper. 
approximately 3 hours and it contains around 120 relative clause constructions ${ }^{6}$.

It is observed that TID favors an internally headed strategy however, the other strategies are also possible: externally headed strategy, doubling the $\mathrm{HN}^{7}$ and free RCs are also observed. The frequency of these strategies is given in Figure 1. An illustrative example of each strategy can be seen in (4$8)$. Note that, we do not consider semantic properties of the relativization strategies in TID in this paper ${ }^{8}$.

Figure 1. Distribution of the occurrence of relativization strategies in a smallscale TID corpus adapted from Kubus, 2016:185)

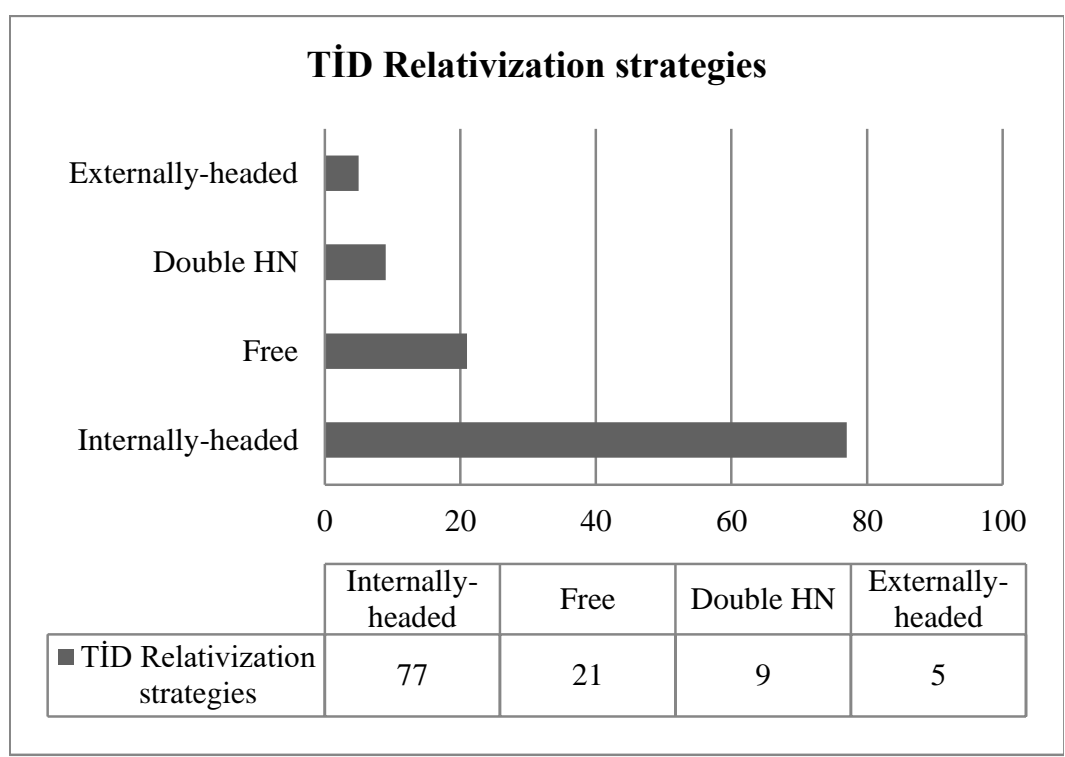

6 For more information (e.g. direct links to the videos) on the methodology, the readers are referred to Kubus (2016).

7 We consider double headed RCs in TID as a separate group, leaving it open whether the constructions are actually internally or externally headed or even correlatives; even though Kubus (2016) takes some occurrences of double headed as internally headed and some as externally headed.

8 Kubus (2016) claims that there is a potential difference between preference for nonmanuals and restrictivity of RCs. There are some investigations regarding nonrestrictive RCs, for example Branchini (2017) claims that nonrestrictive RCs lack non-manual squint in LIS. 
According to Kubus (2016), TID generally favors RC constructions in which the HN occurs within the scope of a non-manual marker, squint. Kubus uses the scope of squint as a diagnostic for the RC. In other words, if the HN is inside the scope of the squint, then the RC is internally headed, if it is outside the scope of the squint, then the RC is externally headed. For instance, the HN GIRL in (4) ${ }^{9}$ which is the subject of the relative clause occurs at the beginning of the clause.

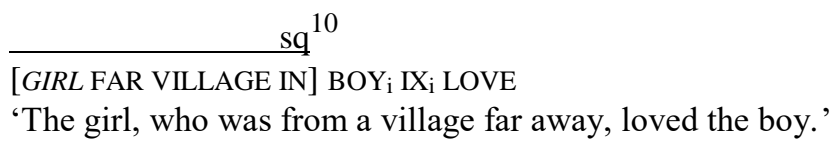

(Kubus, 2016: 208)

The second strategy observed is externally-headed RCs, in which the nonmanual squint does not spread over the head, as in (5). It is observed that there is a pause between the $\mathrm{HN}$ and the $\mathrm{RC}$ and squint occurs only on the RC whereas the brow raise spreads over the $\mathrm{HN}$ and the RC. In this example, another non-manual marker; headshake in the RC is also detected, which can be realized in combination with either squint, brow raise or both.

(5)

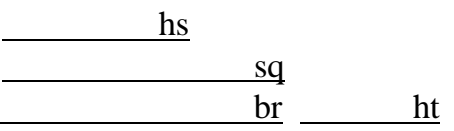

HANGMAN [COMPETITION A-B-C] NOT-WANT

'I did not like hangman, a game which uses letters.'

(Kubus, 2016: 218)

Other than internally headed and externally-headed strategies, there can be $\mathrm{RCs}$ that have no overt $\mathrm{HN}$, i.e. free relatives. The $\mathrm{HN}$ is realized either through the use of the signing space (agreeing verbs in the case of (6)) mostly being introduced in the discourse earlier, or the addressee can derive it from discourse/pragmatic interpretations. Kubus (2016) also categorizes occurrences like in (7), 14 similar cases were determined in his data, as free relatives since there are not any overt HN. However, whether $\mathrm{X}$ can be

\footnotetext{
$9 \quad$ All TiD examples have been taken from Kubus (2016). See Kubus (2016: 311-348) for a full list of RCs in the corpus with English glosses.

10 The scope of non-manual spreading is indicated by lines (or dashed lines for cases in which the spreading was not certain) over glossed manual signs, and the mouthings are shown between square brackets [ ], by convention in sign language linguistics literature. Co-indexation and spatial localization of non-first person with verb and IX signs is given with subscripts (e.g. i, j, k) while co-indexation with first person is indicated with 1 .
} 
interpreted as a grammatical head or not in these cases has to be examined in detail and is beyond the scope of this paper.

(6)

$\frac{\text { sqisep] }_{\text {is }}}{\text { [BITTER }_{1} \text { THROW }_{\mathrm{i}} \text { ] SUGAR }}{ }_{\mathrm{i}}$ GIVE $_{1}{ }^{11}$
'I treated well to the one who treated me badly.'

(Kubus, 2016: 321)

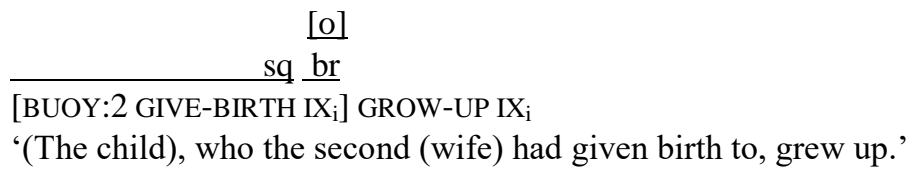

(Kubus, 2016: 183)

In some cases, the head occurs within a token two times, as in (8). Kubus (2016) assumes that utterances like these are double-headed relative clauses based on the existence of squint and pragmatic dependency of one clause on the other. Given that the sentence boundaries in sign languages are not easy to determine (e.g. Crasborn (2008)) it is an open question whether the clause in the squared brackets in (8) is an independent sentence or an internally headed relative clause.

(8)

$\frac{\mathrm{sq}}{\left[\text { MOTHER }_{i} \text { HOME ARRIVE] MOTHER }\right.}$ COME-TO-MIND NEIGHBOR $\mathrm{j}$ iCALL $\mathrm{COME}_{\mathrm{j}}$
'(Her) mother, who had just arrived home, came to her mother's mind and
called (her) mother's neighbor.' 12

\section{$3.1 \quad$ Non-Manual Markers of Relativization in TiD}

So far, we have mentioned various different relativization strategies according to the presence/absence of the head and its position and we have seen that non-manual markers (NMMs): squint, brow raise and headshake seem to be markers of relativization each having varying spreading behavior and

\footnotetext{
11 Agreement verbs are spatially modified in such a way that the starting and the end locations of the verb are associated with subject and object arguments, respectively (Padden, 1990).

12 The translation of the original sentence was leading ambiguity for clarification we added the references for "her" in "(Her) mother, who had just arrived home, came to her mind and called her neighbor." (Kubus, 2016: 315)
} 
frequency of distribution ${ }^{13}$. Table 1 shows the distribution of NMMs in each of the RC types, which suggests that, relativization strategies do not seem to have different non-manual preferences. However, we can say that squint is the most frequent non-manual marker in all identified RC strategies.

Table 1. Distribution of NMMs per relativization strategy in small-scale TiD corpus (adapted from Kubus, 2016: 193)

\begin{tabular}{lccc}
\hline RC type & Squint & Brow raise & Headshake \\
\hline $\begin{array}{l}\text { Internally headed } \\
(\mathrm{n}=75)\end{array}$ & $67(89 \%)$ & $12(16 \%)$ & $17(23 \%)$ \\
$\begin{array}{l}\text { Externally headed } \\
(\mathrm{n}=7)\end{array}$ & $7(100 \%)$ & $1(14 \%)$ & $2(29 \%)$ \\
$\begin{array}{l}\text { Free } \\
(\mathrm{n}=21)\end{array}$ & $15(71 \%)$ & $5(24 \%)$ & $3(14 \%)$ \\
$\begin{array}{l}\text { Double HN } \\
(\mathrm{n}=9)\end{array}$ & $7(78 \%)$ & $2(22 \%)$ & $1(11 \%)$ \\
NMMs in total & $96(86 \%)$ & $20(25 \%)$ & $23(21 \%)$ \\
\hline
\end{tabular}

Given that squint appears in all types of RCs and fully spreads over RCs (Kubus, 2016), this non-manual can be characterized as a predominant marker of RCs in TİD. Dachkovsky \& Sandler (2009) and Sandler (2010) identify squint as a non-manual marker of RCs in ISL as well and claim that it expresses restrictivity and has a pragmatic function which is related to retrieving information, that is accessible for both of the interlocutors.

Other than squint, brow raise is also observed in relativization in TID. Considering the distribution of brow raise, we can say that it does not seem to mark a specific relative strategy and its spreading behavior is not systematic (Kubus, 2016) either. For example, sentence (9) below is one of six occurrences in which only brow raise spreads over the whole RC including the HNs. Note that, brow raise also combines with other NMMs like squint and headshake. The brow raise is suggested to be a marker of topicalization of the HN or RCs with its HN (Kubus, 2016).

13 For a detailed distribution of different of NMMs and their spreading behavior see Kubus (2016). 
(9)

br $E_{S R A_{i}}\left[\mathrm{IX}_{\mathrm{i}}\right.$ COMPUTER USE BEFORE COMPUTER USE IX $\mathrm{IX}_{\mathrm{i}}$ ] ESRA $A_{i}$ COMPUTER PRESS 'Esra, who used the computer earlier pressed on (the keys of) this computer' 14

(Kubus, 2016: 189)

Headshake does not seem to occur alone and its spreading behavior is not systematic, either. In example (6), headshake occurs in the middle of the RC, specifically an object of the RC. However, in the rest of the data headshake appears mostly at the end of $\mathrm{RC}$ or over the $\mathrm{HN}$. It might have a function of emphasis of the RC or the HN itself. The example (10) indicates an occurrence in which both the $\mathrm{HN}$ and the object of the RC have a headshake.

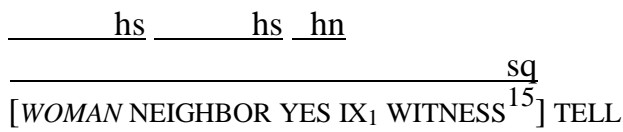

'The female neighbor who said 'yes, I witnessed it', told (everything).'

(Kubus, 2016: 316)

To recapitulate, we can rephrase the descriptive analysis in the following way: squint is a strong syntactic marker of relativization, possibly with the function of restrictivity. Brow raise might signal topicalization of either the $\mathrm{HN}$ or the RC. However, headshake has a prosodic/pragmatic rather than syntactic function (see Section 4).

\subsection{Manual Markers of Relativization in TiD}

The most frequent RCs do not exhibit any manual marker, as seen in (5), (6) and (8). On the contrary, we observe IX coreferential with the (covert) HN, a pointing sign, at the end of RCs as in (7). Such IXs are usually accompanied by brow raise and [o] mouthing. These mouthings might be due to contact with spoken/written Turkish that has 'o' as third singular personal pronoun. IX

14 The original sentence (Kubus, 2016: 189) was referring to the HN computer: 'Esra pressed on (the keys of) this computer that she used earlier.' It was difficult to determine what is the $\mathrm{HN}$ in this case. In this paper we propose the head to be ESRA rather than COMPUTER, because of the existence of clause initial and final IX coreferential with ESRA between the RC and the second occurrence of ESRA.

15 Reports of the utterances as in (10), which are in the form of the dialogue and introduced by verbs such as SAY or THINK are considered as instances of constructed action or more specifically constructed dialogue (see an actual and detailed review on constructed action Cormier, Smith, \& Sevcikova-Sehyr (2016). 
can also be seen at the beginning of the $\mathrm{RC}$, within $\mathrm{RC}^{16}$ or else in both positions (i.e. the beginning and the end). We observe IX doubling in the instance of (9). In addition to the IX, there is another potential relative marker: AYNI 'the same'. It can occur either alone or in combination with a clause final IX as shown in (11) ${ }^{17}$. There is an occurrence of a combination of clause initial, clause-internal, clause final IX and the sign AYNI in (12).

$\underline{\text { br }}$

[o]

sq $\underline{\mathrm{hf}}$

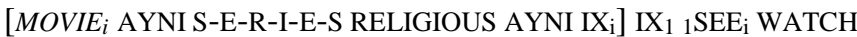

'I watched the movie that is a religious series.' 18

(Kubus, 2016: 258)

(12)

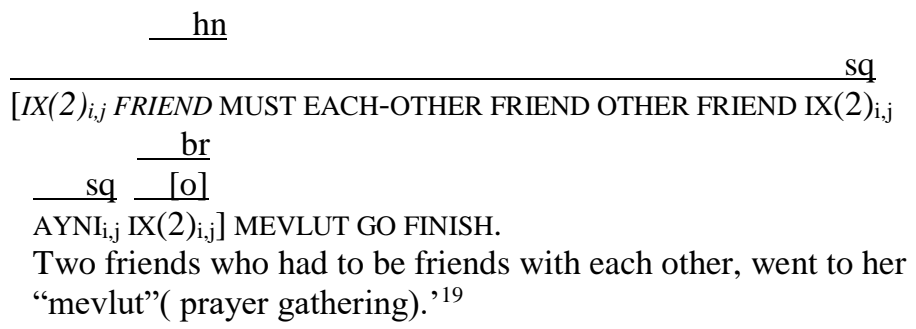

(Kubus, 2016: 203)

When we look at the distribution of the relative elements among the relativization strategies (Table 2), the most frequently used strategies appear with no overt manual marker and clause final IX.

16 Kubus (2016) also analyzes occurrences of IX that are found within the clause (i.e., that are not at the beginning or end of RCs). Due to the low frequencies, we did not include those in this paper. However, these occurrences are worth to analyze on their own, as well.

17 The anonymous reviewer noticed that in the example (11) there is doubling of the manual marker AYNI. Throughout the collected samples in the data of Kubus (2016), doubling of AYNI has been observed only twice. Another example is also given in (13).

18 We have corrected the original translation (Kubus, 2016: 258) by changing 'film' into 'movie'.

19 We have added an explanation to 'mevlut' for the sentence given in Kubus (2016: 203). 
Table 2. Distribution of manual markers per relative strategy

\begin{tabular}{lcccc}
\hline RC type & $\begin{array}{c}\text { No manual } \\
\text { marker } \\
(\mathrm{n}=37)\end{array}$ & $\begin{array}{c}\text { Clause } \\
\text { Initial IX } \\
(\mathrm{n}=21)\end{array}$ & $\begin{array}{c}\text { Clause } \\
\text { Final IX } \\
(\mathrm{n}=49)\end{array}$ & $\begin{array}{c}\text { AYNI } \\
(\mathrm{n}=11)\end{array}$ \\
\hline $\begin{array}{l}\text { Internally } \\
\text { headed }\end{array}$ & $21(28 \%)$ & $19(25 \%)$ & $35(47 \%)$ & $9(12 \%)$ \\
$\begin{array}{l}\text { Externally } \\
\text { headed }\end{array}$ & $4(60 \%)$ & $0(0 \%)$ & $2(29 \%)$ & $0(0 \%)$ \\
$\begin{array}{l}\text { Free } \\
\text { RCs }\end{array}$ & $6(27 \%)$ & $3(14 \%)$ & $10(48 \%)$ & $2(10 \%)$ \\
Double HN & $6(67 \%)$ & $1(11 \%)$ & $2(22 \%)$ & $0(0 \%)$ \\
\hline
\end{tabular}

Internally headed RCs seem to have the most variety, probably due to the high occurrence in the corpus. The descriptive statistics indicate that internally headed and free relative strategies favor clause final IX whereas externallyheaded strategies and doubling HN favor the strategy of not using an overt manual relative element. Moreover, AYNI is observed only in IHRC and Free relatives. Hence, the use of manual markers indicates that it might be dependent on the type of a particular relative strategy.

Kubus (2016) shows that 9 of 23 cases consist of the combination of clause initial IX and clause final IX and argues that the relative element (i.e. clause final IX) at the end of the RC is copied back to clause initial position (p. 199) (cf. Subject pronoun copy, Padden (1988)). Similar occurrence is also observed in HKSL (Tang et al., 2010). They also observe that there is a difference between clause initial and final IX in terms of non-manuals and the latter is rather functioning as a relativizer, which is optional.

We discuss in the following section whether the tendencies of the use of a manual marker can be explained by the discourse function of the $\mathrm{HN}$ and the MC. We analyze the following three strategies: clause final IX, AYNI and no manual relative marker.

\section{Discourse Functions of RCs in TiD}

Kubus (2016) categorizes discourse function of the heads and MCs of the RCs in TID following Aksu-Koç \& Erguvanl1-Taylan (1998)'s analysis of RCs in Turkish $^{20}$. According to this categorization, the RC either introduces the referent of the head for the first time into the discourse, or re-introduces a referent, i.e. a referent is brought into focal consciousness. The following functions are proposed for the MC: identification (establishing the referent),

20 Aksu-Koç \& Erguvanl1-Taylan (1998)'s analysis is inspired by Chafe (1987) and Fox \& Thompson (1990). 
re-identification (given referents are re-introduced with the provided information) and characterization (expressing additional descriptive information about the head). Illustrative examples of these categories in TiD with their contexts, indicated by numbers for each discourse chunk, are given below in (13-14), from Kubus (2016: 256-265).

$$
\frac{\frac{\mathrm{br}}{\mathrm{hn}}}{\mathrm{co}}, \frac{\mathrm{hn}}{\mathrm{sq}}
$$

a. [BUOY:1 MARRY FINISH IX $\mathrm{X}_{\mathrm{i}}$ ] SINGLE $\mathrm{CL}_{\mathrm{j}} \mathrm{MEET}_{(\mathrm{i}, \mathrm{j})}$

'The first (woman), who was already married, met (the woman), who was single.'

(re-introduced HN- re-identified MC)

(Kubus, 2016: 262)

b. Context: (in a village) there are three women. One of them is single while two of them are married. The single woman is jealous of the married women because they are visiting each other.

(0003): There were three women, who had known each other for years.

(0004): One woman was married.

(0005): Another woman married soon after.

(0006): The other woman was still single.

(0016): The first (woman), who was already married, met the single woman.

...

(Kubus, 2016: 263)

(14)

$$
\begin{aligned}
& \text { [o] } \\
& \underline{\mathrm{hn}} \\
& \text { sq } \underline{b r} \\
& \text { a. [FOOT HEEL } \left.L_{i} \text { HARD AND ELBOW EDGE }{ }_{j} \text { HARD EXIST IX }{ }_{i, j}\right] \text { LEMON } \\
& \underline{\mathrm{hn}} \\
& \text { CUT CL-CREAM IX } \mathrm{X}_{\mathrm{i}} \text { FOOT HAND SOFT BECOME } \\
& \text { 'Use lemon rind to soften heels and elbows, which have hard } \\
& \text { surfaces' } \\
& \text { (introduced head- characterizing modifying clause) }
\end{aligned}
$$


b. Context: The signer wants to inform his/her audience of the best way to soften dry heels and elbows.

Sequences from (0004) to (0006):

(0004) There are various solutions for things disturbing our lives.

(0005) Use lemon rind to soften heels and elbows, which have hard surfaces

(0006) Your elbows and heels will now be very soft.

(Kubus, 2016: 262)

In this section we focus on the abovementioned discourse-based categorization and further split the data (i.e. introduced and re-introduced HNs as well as identified, re-identified and characterized MCs) according to: (i) absence/presence of the HN; (ii) non-manual markers (i.e., squint, brow raise and head shake), and (iii) no marking -manual markers of RCs, with the aim to determine potential correlation of relativization strategies as well as (non)-manual markers with discourse function of HNs and MCs.

An overview of the relativization strategies and discourse functions of the head of the MC are given below in Table $3^{21}$. For all types of RCs identified so far, we observe that they occur frequently when the head is discourse old, the same can be said for the MCs as well. The strategy of double HN might be triggered if the referent of the head is introduced for the first time and the MC either identifies or characterizes the HN.

Table 3. Frequency of RC types grouped according to discourse functions of the HNs and the MCs

\begin{tabular}{lcllc}
\hline $\begin{array}{l}\text { Discourse function } \\
\text { of HNs and MCs }\end{array}$ & $\begin{array}{c}\text { Internally } \\
\text { headed }\end{array}$ & $\begin{array}{c}\text { Externally } \\
\text { headed }\end{array}$ & $\begin{array}{c}\text { Free } \\
\text { RCs }\end{array}$ & $\begin{array}{c}\text { Double } \\
\text { HN }\end{array}$ \\
\hline HN: introduced & $20(27 \%)$ & $2(29 \%)$ & $5(24 \%)$ & $4(44 \%)$ \\
HN: re-introduced & $55(73 \%)$ & $5(71 \%)$ & $16(76 \%)$ & $5(56 \%)$ \\
MC: identification & $12(16 \%)$ & $0(0 \%)$ & $2(10 \%)$ & $2(22 \%)$ \\
MC: re-identification & $49(65 \%)$ & $5(71 \%)$ & $15(71 \%)$ & $4(44 \%)$ \\
MC: characterization & $14(19 \%)$ & $2(29 \%)$ & $4(19,1 \%)$ & $3(33 \%)$ \\
\hline
\end{tabular}

21 The descriptive statistics for the HN and MC are given separately. However, there is another possibility to show the table in a combined way showing 6 combinations. Kubus (2016) indicated that the most observed combination is Re-introduced Head with reidentifying $\mathrm{MC}$ with a percentage of 69. Due to page limitations, the authors preferred to show them separately. We thank the anonymous reviewer for suggestion of presenting the results in this way. 
When we examine whether the distribution of non-manuals depends on the discourse functions of the head and MC (Table 4), we observe two important tendencies. Both squint and headshake or a combination of them is highly favored with re-introduced heads and re-identified MCs. The tables show that headshake has rather pragmatic/semantic and even prosodic function with squint which conveys shared information. When compared to other nonmanual markers, brow raise might have a different function conveying new information since it has slightly more introduced head noun and characterizing MC.

Table 4. Frequency of NMMs grouped according to discourse functions of the HNs and the MCs

\begin{tabular}{lccc}
\hline $\begin{array}{l}\text { Discourse function } \\
\text { of HNs and MCs }\end{array}$ & Squint & Brow raise & Headshake \\
\hline HN: introduced & $26(27 \%)$ & $8(40 \%)$ & $3(13 \%)$ \\
HN: re-introduced & $70(73 \%)$ & $12(60 \%)$ & $20(87 \%)$ \\
MC: identification & $15(14 \%)$ & $2(10 \%)$ & $0(0 \%)$ \\
MC: re-identification & $64(67 \%)$ & $10(50 \%)$ & $20(87 \%)$ \\
MC: chracterization & $17(18 \%)$ & $8(40 \%)$ & $3(13 \%)$ \\
\hline
\end{tabular}

If we consider the discourse function of the $\mathrm{HN}$ and MC (Table 5), we can observe a special function of AYNI. That is, it appears in the context of reintroduced heads and re-identified MCs and it is fairly rarely observed with first introduced heads and identified MCs. The case of AYNI in which the head is introduced for the first time is illustrated in (14). In this example, the signer wants the addressee to understand what this fountain is. Even though the passage is in the form of a monologue, the signer assumes that the target group has previous knowledge of these types of fountains in the village. This is an example of 'shared information' (Dachkovsky \& Sandler, 2009). Squint characterizes mutually retrievable or "shared" information in some sense, but it also typically identifies relative clauses, remote past, and other structures (p. 293). 
'The first and second women went to the fountain where (people from all) villages fill (their buckets) with water'22

(Kubus, 2016: 275)

Table 5. Frequency of manual markers grouped according to their cooccurence with HNs and the MCs of various discourse functions

\begin{tabular}{lccc}
\hline $\begin{array}{l}\text { Discourse function } \\
\text { of HNs and MCs }\end{array}$ & $\begin{array}{c}\text { No manual } \\
\text { Marker }\end{array}$ & $\begin{array}{c}\text { Clause } \\
\text { Final IX }\end{array}$ & AYNI \\
\hline HN: introduced & $9(24 \%)$ & $17(35 \%)$ & $1(9 \%)$ \\
HN: re-introduced & $28(76 \%)$ & $32(65 \%)$ & $10(91 \%)$ \\
MC: identification & $4(11 \%)$ & $9(18 \%)$ & $0(0 \%)$ \\
MC: re-identification & $26(70 \%)$ & $29(59 \%)$ & $9(82 \%)$ \\
MC: chracterization & $7(19 \%)$ & $11(22 \%)$ & $2(18 \%)$ \\
\hline
\end{tabular}

\section{Discussion}

In this paper, we revisited the findings of Kubus (2016) and we did further descriptive analyses of his data, approaching RCs from a discourse functional perspective. In the following we recap the findings of Kubus referred to in this study, summarize our contributions, discuss potential factors determining relativization strategies, the interaction between text structure and sentence, grammaticalization pathways in relativization and finally we mention modality effects in the realization of RCs in TID, comparing them with those in Turkish.

The main characteristics of RCs in TID, identified by Kubus (2016) and presented above can be summarized under three headings: (i) the most frequent relativization strategy, (ii) the NMMs of $\mathrm{RCs}$, and (iii) manual markers of RCs. Internally headed strategy is the most prominent one. However, other strategies such as externally headed RCs, RC containing doubling of HN and free RCs are observed as well. Squint is the most observed syntactic non-manual marker. Additionally, brow raise and

22 Given the feedback by the anonymous reviewer, we used a better wording for the sentence given in Kubus (2016: 275) 
headshake can optionally mark RCs. Among these, the headshake cannot spread over the entire RC. As for the manual markers, no overt manual marker and clause final IX seem to occur optionally.

Distribution of each non-manual and manual marker for each relativization strategy has been further analyzed (statistically) for this study. We have not observed differences in tendencies of the use of non-manual markers among different relativization strategies. As for the use of the manual markers, we have determined that clause final IX favors internally headed and free relative strategies; on the other hand, no relative marker favors externally headed RC and RCs with double HN.

We have shown that these varying RC strategies as well as distribution of (non)-manual markers can also be explained by discourse functions of the head and MC previously identified by Kubus (2016: 269). The two most prominent functions are (i) introducing the $\mathrm{HN}$ that has not been introduced into discourse earlier with an identifying $\mathrm{MC}$, so that the addressee can infer the identity of the referent using this information, (ii) re-introducing both the $\mathrm{HN}$ and the MC to either disambiguate the referents or to help the addressee identify the referent. When we look at the descriptive statistics, the findings appear to be threefold: (i) the occurrence of double $\mathrm{HN}$ is slightly higher in the condition of introduced head and characterizing $\mathrm{MC}$, (ii) brow raise occurs more when the head is introduced into the text for the first time and MC has characterizing function. On the other hand, headshake is used most frequently when the head is re-introduced and MC is re-identifying (iii) AYNI is observed almost in all conditions where the head is re-introduced and the $\mathrm{MC}$ is re-identifying.

The use of both internally headed and externally headed strategies in TID are not unique to this sign language, ASL has been observed to have both constructions as well (Wilbur, 2017). In this paper we showed that strategy of doubling $\mathrm{HN}$ is slightly more preferred over internally and externally headed strategy in TID. If the head and the MC are introduced into the text for the first time, we claim that it might be a possible strategy for marking low accessible information status. However, there is still a need for a detailed analysis for both headless constructions and doubling HN. Among many others, the following questions still remain unanswered: are headless constructions in TID really headless? Why does the HN occur twice in some instances? Is head doubling a strategy for domain marking of the RCs? Are these constructions indeed internally headed or are they also externally headed constructions?

Regarding the non-manual elements occurring in RCs in TID, we can see that squint is a good candidate for being a syntactic marker. No matter in which relativization strategy, its occurrence is fairly high, compared to other non-manuals like brow raise and headshake. Kubus (2016) has already 
hypothesized that squint has grammaticized from a discourse marking element into a syntactic one. However, squint does not seem to be syntactic marker for RCs in ASL (Wilbur, 2017) and DGS (Pfau \& Steinbach, 2005). The competition between squint and brow raise can be explained at the syntactic level, e.g. brow raise also marking topicalization. Kubus (2016) further suggests that this difference can be explained by semantic properties of RCs, which are worth investigating further defining the criteria for (non-) restrictivity of RCs in TID. However, there is another non-manual, headshake, in RCs, the occurrence of which seems to be unique to TID. Kubus (2016) observes that its scope characteristics are not very systematic and it does not spread over the clause. Even though there is a need for detailed investigation, our paper shows that headshake has a strong pragmatic function: reactivating the referents that have been introduced earlier in the text. We have to keep in mind that headshake also has different functions in TID such as marking negation (in addition to head tilt, e.g. Zeshan (2006)) and content questions (Zeshan (2006), Göksel \& Kelepir (2013)). An interaction between the occurrences of the headshake in interrogatives and RCs might be another possible evidence for headshake to have pragmatic function or even being grammaticized into both functions.

As for manual markers in relativization in TID, this paper has pointed out that the use of AYNI can be explained by the discourse function. It mostly occurs when the head and the MC are introduced earlier into the text. Mosella (2011) indicates that LSC has a similar manual marker in RCs: MATEIX 'the same', which has a nominalizing function, and has gone through grammaticalization over time. Even though AYNI does not occur very frequently compared to the other manual strategies, TID signers also do show a tendency to use this manual marker. We hypothesize that these two unrelated sign languages might exhibit similar grammatical pathways for the manual relativization marker 'the same'. But the question, why AYNI is not preferred over the clause-final IX, still remains to be answered. We suggest that AYNI in TID, has not grammaticalized (yet), but like headshake it rather has a pragmatic function in relativization, reactivating the referents that are introduced earlier into the text.

What about the optional use of IX signs in TID RCs? Why do they occur slightly more in the conditions in which the heads are introduced the first time and the MCs are in the form of identification? As in the doubling head strategy, does it signal a function of reactivating less accessible information? We suggest that its main function is anaphoric, hence being used to disambiguate and track referents introduced by the HN. Additional analyses have to be performed to determine its spatial distribution, duration and most importantly the individual differences among the signers in their usage of it. The use of IX is not unique to TID either. Pfau (2011) and Pfau \& Steinbach 
(2006, 2016) have already hypothesized that there is grammaticalization of pointings into relative pronouns also, for example, in DGS. As Kubus (2016) pointed out, the clause final IX might be grammaticized into a manual marker for relativization in TID. Moreover, we hypothesize that the distribution of especially clause final IX might be explained by the distance between the head and the matrix clause (grammatical weight). In other words, the more distant the $\mathrm{HN}$ in the $\mathrm{RC}$ is, the more difficult it is to be retrieved and hence the need to use a pronominal like element IX. However, the exact aspects of the grammatical weight and the heuristics of its measurement as well as the extend of its explanatory power regarding competition of the (non)manual relativizers are yet to be determined.

We have discussed RCs in TíD in terms of discourse functions. We speculate that optionality and competition of RC markers might appear also due to the fact that some of them (e.g. IX) are still in the process of grammaticalization, potentially from general discourse markers to more specific markers of RCs. Such process of grammaticalization has been reported to take place in other sign languages (Dachkovsky (2015) finds traces of grammaticalization of squint in ISL) as well as geographically and genetically unrelated spoken languages (Tocharian, Quechua, Georgian and Basque, for details see Hendery (2010)). Unfortunately, we do not have historical TID data to compare in order to trace the grammaticalization paths of the abovementioned (potential) relativizers. It might still be an option to look at the data from different generations of signers to see whether we can track the grammaticalization of the abovementioned markers.

Finally we should also compare relativization strategies in TiD and Turkish (the contact spoken language) in order to delineate (possible) modality (in)dependent properties of two languages. First, in terms of the (linear) order of the HN with respect to the MC, Turkish is primarily head final while TiD is primarily head initial. Second, in terms of the relation of the HN with respect to the embedded RC, TID has (primarily) internal, external and free headed constructions while Turkish shows externally headed RCs. Third, in terms of the usage of relativizers, in TID squint frequently marks all identifies RCs while other (non)manual markers (e.g. eye brow raise, IX) appear optionally and in competition with each other and their distribution is determined either by semantics (manual markers) or discourse. On the other hand, Turkish RCs do not contain complementizers, overt whelements or relative pronouns but can (optionally) include resumptive pronouns (Aydın, 2007). Additionally, in Turkish RCs are formed via (verb final) participle constructions determined by morphological markers of different complexity according to the target of the relativization. Namely, when the target of the relativization is subject, subject relativization (SR) strategy is used and when the target of the relativization is object/non-subject, 
object relativization (OR) strategy is used (Underhill, 1972). That is, SR is marked by one of the (-(y)An, -Ir/-Ar, -mAz, -mIş) suffixes, while object RC is marked via (-DIK, $-(\mathrm{y}) \mathrm{Ac} A K)$. Moreover, SR requires no agreement morphology while OR requires agreement in person and number with the (overt) subject (for details of different analyses discussing the cause of such dichotomy in RCs see (Çağrı, 2005; Hankamer \& Knecht, 1976; Kornfilt, 1984; Özsoy, 1994; among others). In sum, the two contact languages articulated in different modalities seem to differ with respect to the position of the $\mathrm{HN}$, relation of the $\mathrm{HN}$ to $\mathrm{MC}$ and markers of relativization.

\section{Conclusion}

This study has shown that the occurrence of varying RC strategies as well as distribution of (optional) (non)manual relativizers in TID can be explained by the discourse functions of the head and MC. Hence, we emphasize the role of discourse in explaining linguistic phenomena in sign languages. Being only at the beginning of this research we admit a need for further investigation of RCs on properties such as target of relativization, semantics (restrictivity/nonrestrictivity) and information structure. In addition, the findings of the present study need to be tested experimentally with larger population of signers from various generations. It is also important to look at bigger corpora for intersigner differences when it comes to RCs.

\section{References}

Aksu-Koç, A., \& Erguvanl1-Taylan, E. (1998). The functions of relative clauses in narrative discourse. In The Mainz Meeting. Proceedings of the seventh international conference on Turkish linguistics (pp. 271-284). Wiesbaden: Harrasowitz Verlag.

Andrews, A. D. (2007). Relative clauses. In T. Shopen (Ed.), Language typology and syntactic description (2nd ed., Vol. 2, pp. 206-236). Cambridge: CUP.

Aydın, Ö. (2007). The comprehension of Turkish relative clauses in second language acquisition and agrammatism. Applied Psycholinguistics, 28(02), 295-315. https://doi.org/10.1017/S0142716407070154

Branchini, C. (2015). On relativization and clefting: An analysis of Italian Sign Language (Vol. 5). Berlin: Mouton de Gruyter.

Branchini, C. (2017, June). Digging up the core features of (non)restrictiveness in sign languages' relative constructions. Presented at the Formal and Experimental Approaches to Sign Language Theory - FEAST 2017, Reykjavík, Iceland.

Branchini, C., \& Donati, C. (2007). Italian Sign Language relatives: A contribution to the typology of relativization strategies. In A. Liptàk (Ed.), Correlatives: Theory and typology (pp. 157-191). Amsterdam: Elsevier.

Branchini, C., \& Kelepir, M. (2017). Coordination \& Subordination. In J. Quer, C. Cecchetto, C. Donati, C. Geraci, M. Kelepir, R. Pfau, \& M. Steinbach (Eds.), 
SignGram Blueprint: A Guide to Sign Language Grammar Writing (pp. 404-490). Walter de Gruyter GmbH \& Co KG.

Brunelli, M. (2011). Antisymmetry and Sign Languages: A Comparison between NGT and LIS. Utrecht: LOT.

Çağrı, İ. M. (2005). Minimality and Turkish relative clauses (PhD Thesis). University of Maryland College Park. Retrieved from https://drum.lib.umd.edu

Cecchetto, C., \& Donati, C. (2016). Relativization in Italian Sign Language: the missing link of relativization. In R. Pfau, M. Steinbach, \& A. Herrmann (Eds.), A Matter of Complexity: Subordination in Sign Languages (Vol. 6, pp. 182-203). Berlin: Mouton de Gruyter.

Cecchetto, C., Geraci, C., \& Zucchi, S. (2006). Strategies of relativization in Italian Sign Language. Natural Language \& Linguistic Theory, 24(4), 945-975. https://doi.org/10.1007/s11049-006-9001-x

Chafe, W. (1987). Cognitive constraints on information flow. In R. Tomlin (Ed.), Coherence and grounding in discourse (Vol. 11, pp. 21-55). Amsterdam and Philadelphia: John Benjamins.

Cinque, G. (2013). Typological Studies: Word Order and Relative Clauses. Hoboken: Taylor and Francis. Retrieved from http://public.eblib.com/choice/publicfullrecord.aspx?p=1619425

Cole, P. (1987). The structure of internally headed relative clauses. Natural Language and Linguistic Theory, 5(2), 277-302. https://doi.org/10.1007/BF00166587

Cormier, K., Smith, S., \& Sevcikova-Sehyr, Z. (2016). Rethinking constructed action. Sign Language \& Linguistics, 18(2), 167-204. https://doi.org/10.1075/s1l.18.2.01cor

Crasborn, O. (2008). How to recognise a sentence when you see one. Sign Language \& Linguistics, 10(2), 103-111. https://doi.org/10.1075/s1l.10.2.03cra

Dachkovsky, S. (2015, October). Grammaticalization of facial intonation: The case of squint in ISL relative clauses. Poster presented at the Nonmanuals at the Gesture Sign Interface (NaGSI), Göttingen.

Dachkovsky, S., \& Sandler, W. (2009). Visual Intonation in the Prosody of a Sign Language. Language and Speech, 52(2/3), 287-314. https://doi.org/10.1177/0023830909103175

De Vries, L. (1993). Forms and functions in Kombai, an Awyu language of Irian Jaya. Canberra: Australian National University.

De Vries, M. (2002). The syntax of relativization. Utrecht: LOT.

Fox, B. A., \& Thompson, S. A. (1990). A Discourse Explanation of the Grammar of Relative Clauses in English Conversation. Language, 66(2), 297-317. https://doi.org/10.2307/414888

Göksel, A., \& Kelepir, M. (2013). The phonological and semantic bifurcation of the functions of an articulator: HEAD in questions in Turkish Sign Language. Sign Language and Linguistics, 16(1), 1-30.

Hankamer, J., \& Knecht, L. (1976). The role of the subject/non-subject distinction in determining the choice of relative clause participle in Turkish. Harvard Studies in Syntax and Semantics, 2, 197-219.

Hendery, R. (2010). Grammaticalisation of discourse marking elements in relative clauses. In R. Hendery \& J. Hendriks (Eds.), Grammatical Change: Theory and Description (pp. 105-122). Canberra: Australian National University Press. 
Ichida, Y. (2010). Introduction to Japanese Sign Language: lconicity in language. Studies in Language Sciences, 9, 3-32.

Kornfilt, J. (1984). Case marking, agreement, and empty categories in Turkish ( $\mathrm{PhD}$ dissertation). Harvard University.

Kubus, O. (2016). Relative Clause Constructions in Turkish Sign Language (PhD dissertation). Universität Hamburg. Retrieved from http://ediss.sub.unihamburg.de/volltexte/2016/7909/pdf/Dissertation.pdf

Liddell, S. (1978). An introduction to relative clauses in ASL. In P. Siple (Ed.), Understanding language through sign language research (pp. 59-90). New York: Academic Press.

Liddell, S. (1980). American Sign Language syntax. The Hague: Mouton.

Mosella, M. (2011, June). The position of fronted and postposed relative clauses in Catalan Sign Language. Presented at the Formal and Experimental Approaches to Sign Language Theory - FEAST 2011, Venice.

Nunes, J., \& de Quadros, R. M. (2008). Phonetically realized traces in American Sign Language and Brazilian Sign Language. In J. Quer (Ed.), Signs of the time. Selected papers from TISLR 2004 (pp. 177-190.). Seedorf: Signum-Verlag.

Özsoy, A. S. (1994). Türkçede ortaç yapısı [Relative Clause Structure in Turkish]. In Dilbilim Araştırmaları, [Linguistic Investigations] (pp. 21-30). Ankara: Hitit Yayınevi.

Padden, C. (1988). Interaction of Morphology and Syntax in American Sign Language. New York and London: Garland Publishing, Inc.

Padden, C. (1990). The Relation Between Space and Grammar in ASL Verb Morphology. In L. Ceil (Ed.), Sign Language Research: Theoretical Issues (pp. 118-132). Washington, DC: Gallaudet University Press.

Pfau, R. (2011). A point well taken: On the typology and diachrony of pointing. In D. J. Napoli \& G. Mathur (Eds.), Deaf around the world. The impact of language (pp. 144-163). Oxford: Oxford University Press.

Pfau, R., \& Steinbach, M. (2005). Relative clauses in German Sign Language: Extraposition and reconstruction. In L. Bateman \& C. Ussery (Eds.), Proceeding of the North East Linguistic Society (NELS 35) Vol. 2 (pp. 507-521). Amherst, MA: GLSA.

Pfau, R., \& Steinbach, M. (2006). Modality-independent and modality-specific aspects of grammaticalization in sign languages (Linguistics in Potsdam 24). Potsdam: Universitäts-Verlag. Retrieved from https://publishup.uni-potsdam.de/opus4ubp/frontdoor/deliver/index/docId/1005/file/linguistics24.pdf

Pfau, R., \& Steinbach, M. (2016). Complex sentences in sign languages: Modality typology - discourse. In R. Pfau, M. Steinbach, \& A. Herrmann (Eds.), A matter of complexity: Subordination in sign languages (pp. 1-35). Berlin: De Gruyter Mouton.

Sandler, W. (2010). Prosody and syntax in sign languages. Transactions of the Philological Society, 108(3), 298-328. https://doi.org/10.1111/j.1467968X.2010.01242.x

Tang, G., \& Lau, P. (2012). Coordination and subordination. In R. Pfau, M. Steinbach, B. Woll, \& B. Woll (Eds.), Sign Languages: An International Handbook (pp. 340364). Berlin: De Gruyter Mouton. 
Tang, G., Lau, P., \& Lee, J. (2010, October). Strategies for relativization in HKSL. Presented at the Theoretical Issues in Sign Language Research (TISLR) 10, Purdue University, West Lafayette, IN.

Underhill, R. (1972). Turkish participles. Linguistic Inquiry, 3, 87-99.

Wilbur, R. (2017). Internally-headed relative clauses in sign languages. Glossa: A Journal of General Linguistics, 2(1), 1-34. https://doi.org/10.5334/gjgi.183

Zeshan, U. (2006). Negative and interrogative structures in Türk İşaret Dili (Turkish Sign Language). In U. Zeshan (Ed.), Interrogative and Negative Constructions in Sign Languages (pp. 128-164). Nijmegen: Ishara Press. 